\title{
Daily Stressors and Marital Interactions Affect Diurnal Cortisol and Alpha-Amylase Rhythm in Spouses of Persons with Mild Cognitive Impairment
}

Tina Savla, Karen A. Roberto, Rosemary Blieszner

Center for Gerontology \& Dept. of Human Development, Virginia Polytechnic Institute and State University

Introduction

- Mild Cognitive Impairment (MCl) is

ry out a series of steps in sequence
Spouses defined as "Care Partners" are the first line of support

- Strescors may pile up over time and cortibute tigns of distress and well-being and the family's overall quality of life

\section{Research Aims}

To document daily symptoms and behaviors of persons with $\mathrm{MC}$

.

well-being of care partners

partner's physiological indicators of heatth (Diurnal needs and other stressors on spouse care

\section{Study Sample}

30 care partners of a spouse diagnosed with $\mathrm{MCl}$ at a memory clinic. Dementia \& potential reversible loss and confusion (e.g., depression, nutritional deficiencies, health problems)

Study Measures

7 consecutive daily diary interviews +4 days of Saliva collection

Primary Stressor: Memory \& Behavior Problem Checklist calibrated for daily reporting on 5 behavioral

Secondary Role Strain: Asked questions about: Time Spent, In-depth assessment of Non-Caregiving

Study Outcomes:

- Daily Psychological Distress (Negative \& Positive Affect)

- Saliva collected 5 times each day (wake up, 30 mins after waking, lunch, evening and before

Analysis

We used 2-level multilevel modeling (MLM) as implemented in STATA XTMIXED to examine daily We used 2-level multilevel modeling (MLM)

We used a 3-level MLM with robust standard errors to simultaneously estimate the diurnal cortisol

slope and its acceleration as well as model how daily variations in
day variations in diurnal salivary cortisol slope and AA slope.
Results

Result 1: Distinct Sundowning evident by the increase memory and behavioral problems towards the end of the day

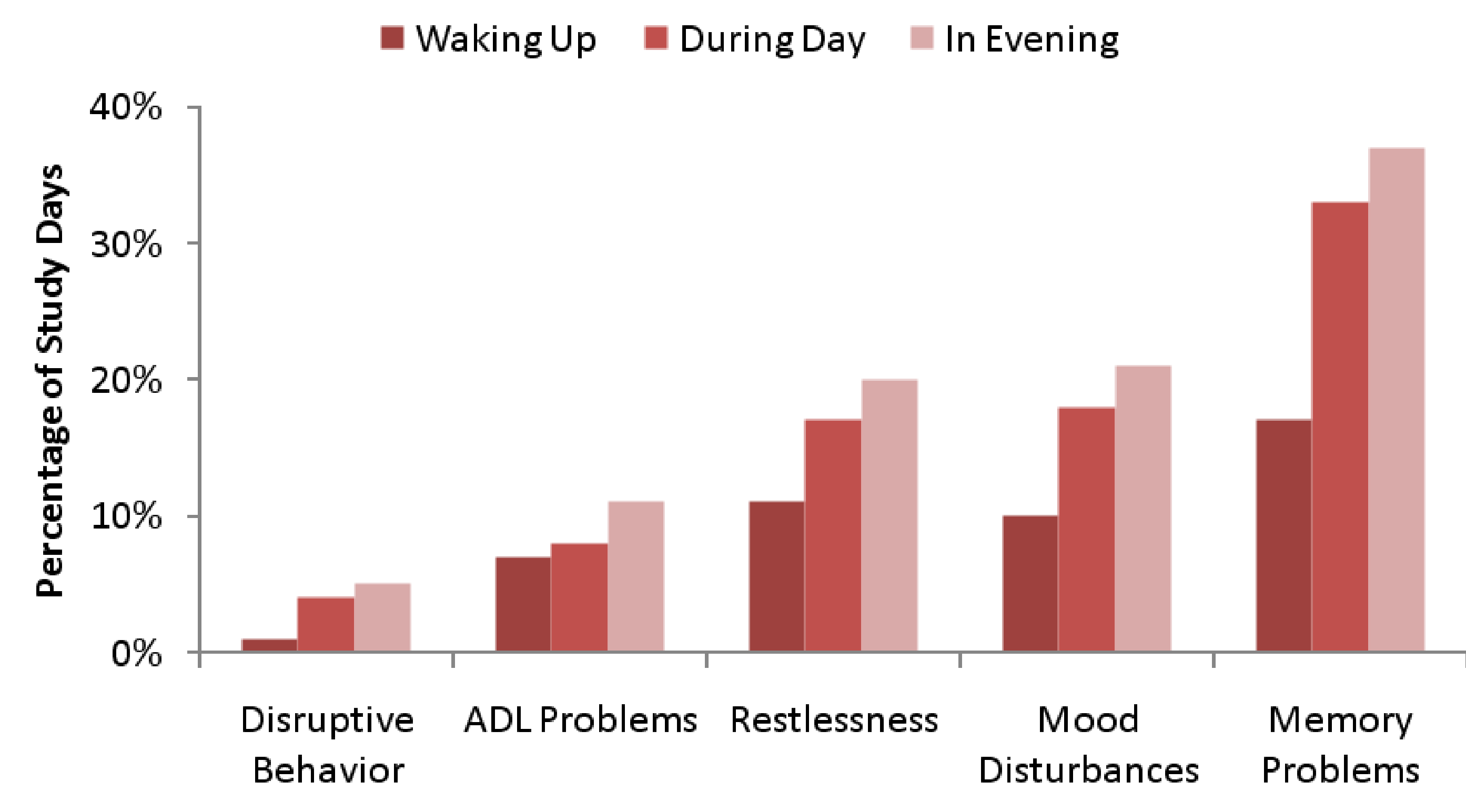

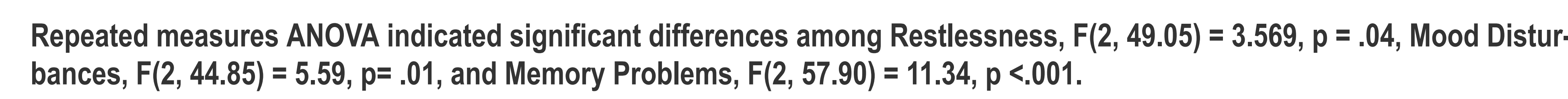

Result 2: Daily Primary \& Secondary Stressor Pile Up Influenced Psychological Affect

\begin{tabular}{|c|c|c|}
\hline & $\begin{array}{l}\text { Positive } \\
\text { Affict }\end{array}$ & 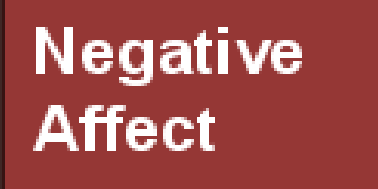 \\
\hline Zaily Primary Stressors & & \\
\hline Number of Behavioral Problems During the Day & & $-1.36(0.44)$ \\
\hline Number of Behavioral Problems in Evening & $-3.40(0.96)^{*}$ & $1.26(0.42)$ \\
\hline Daily Secondary Strossors & & \\
\hline Pleasant Martital Interactions & $1.68(0.57)^{*}$ & \\
\hline Unpleasant Marital Interactions & & 0.73(0.35)" \\
\hline Any Cut Back of Schedulued Adtivities & $-3.44(1.40)^{*}$ & $1.26(0.58)^{t}$ \\
\hline \begin{tabular}{|l|} 
Any Noncare-related Stressors \\
\end{tabular} & & $1.12(0.56)^{x}$ \\
\hline
\end{tabular}

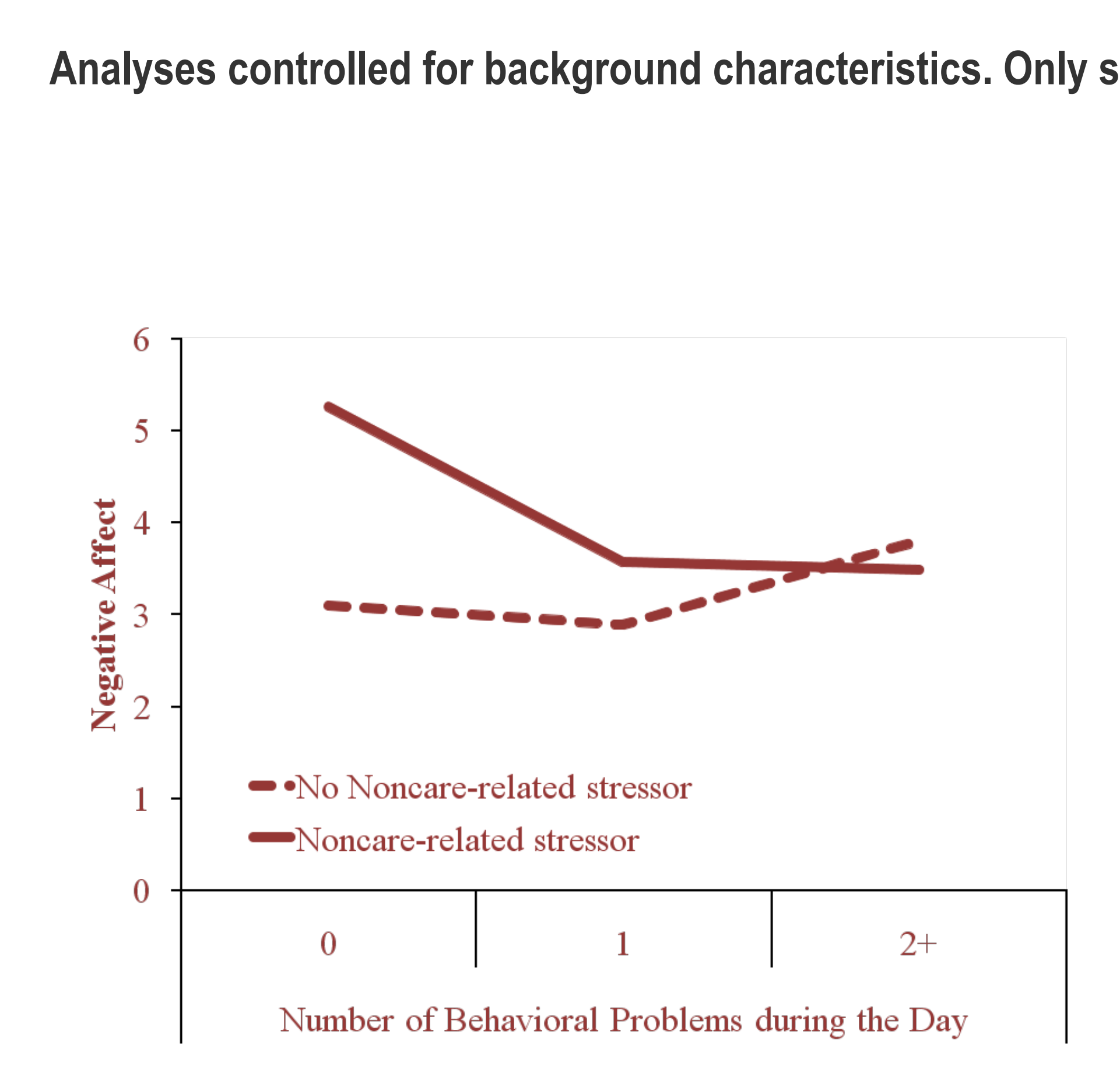

Daily negative affect affected by noncare-relatede
number of behavioral problems during the day.

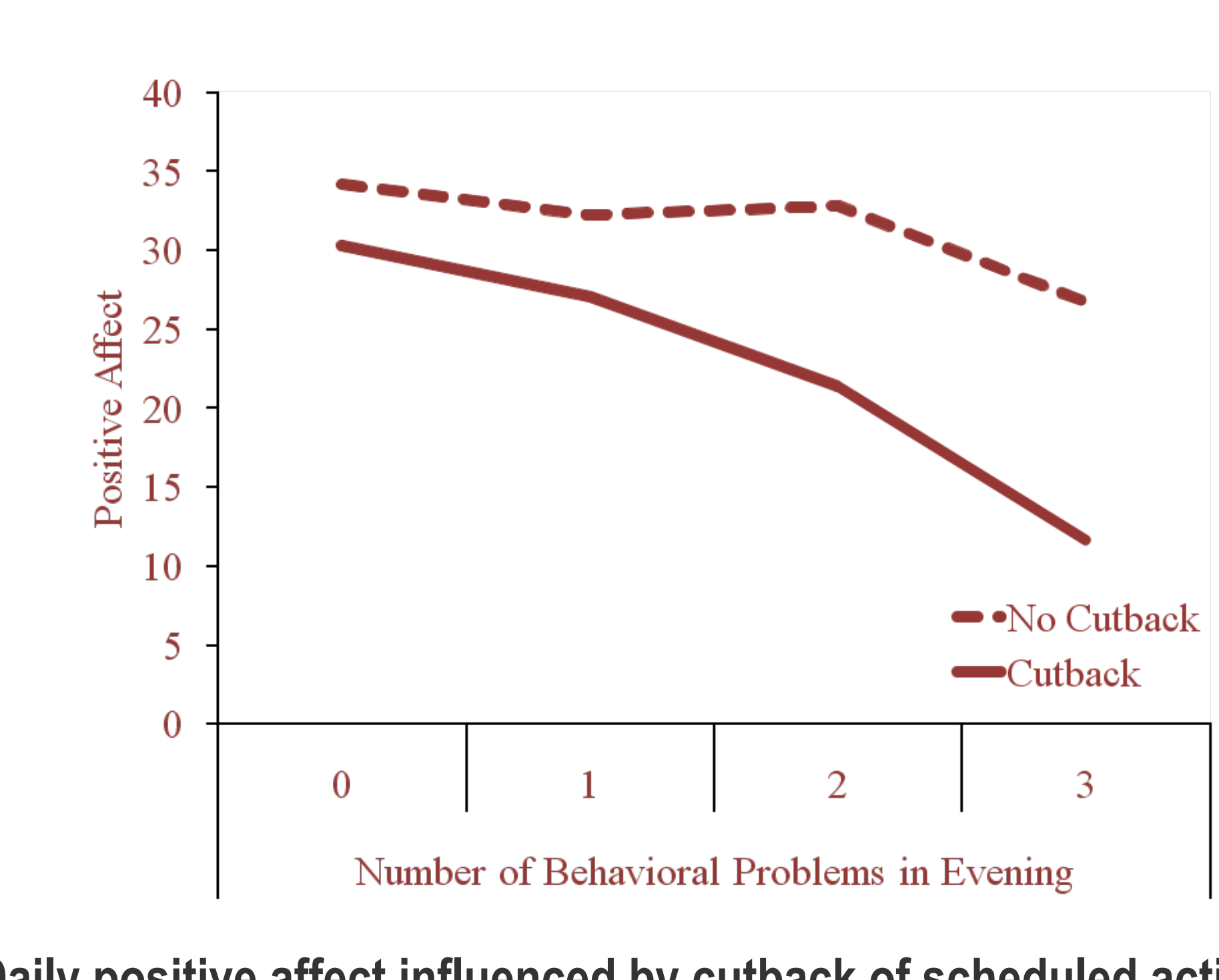

Daily positive affect influenced by cutback of scheduled activ-
ities and number of behavioral problems during the day (not
Result 3: Within-person analysis show that daily stressors affect the diurnal cortisol and SAA slope controlling for other situational factors

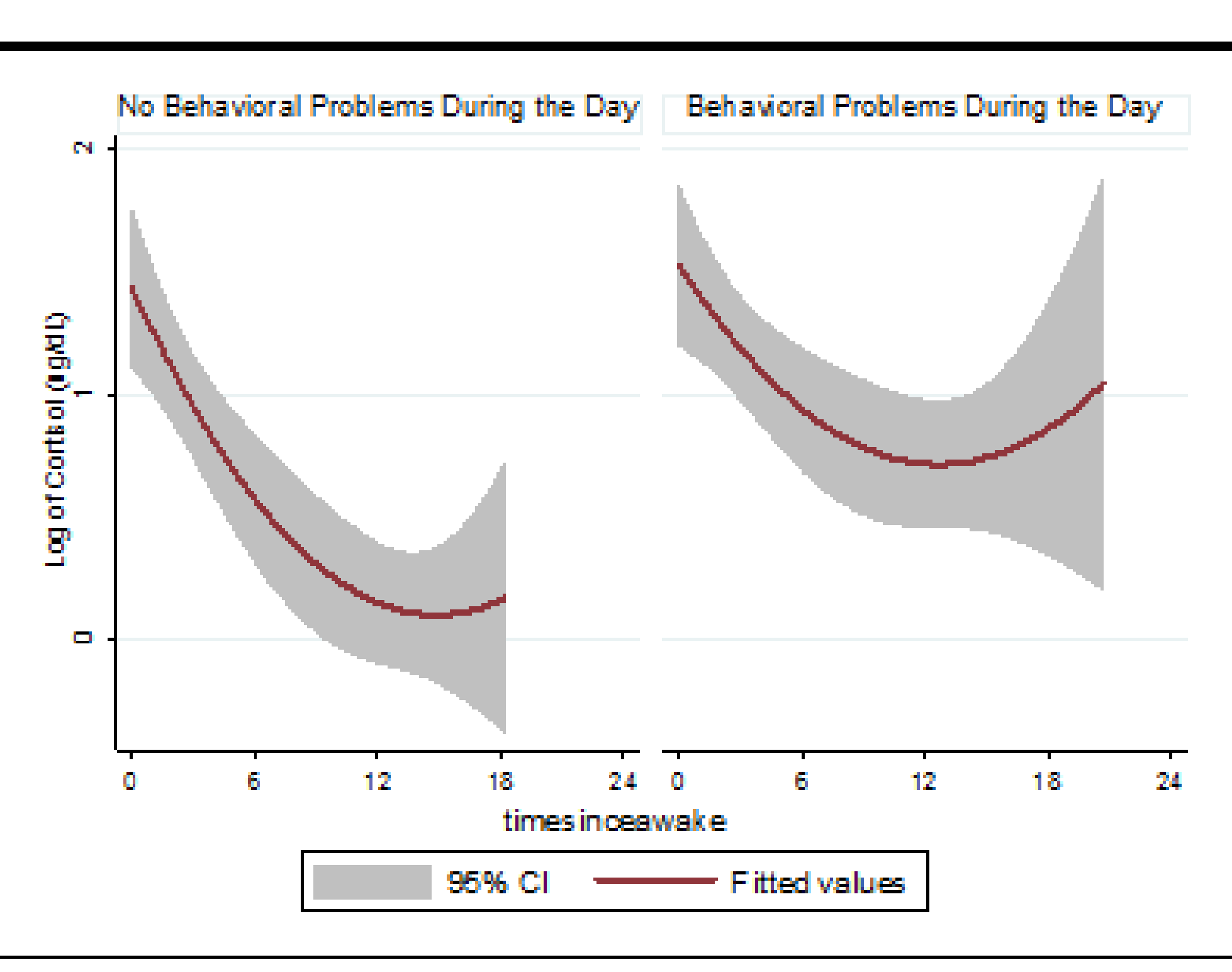

On days memoror-reltated problems were reported, significantly
higher levels of cortisol were found among care partiers

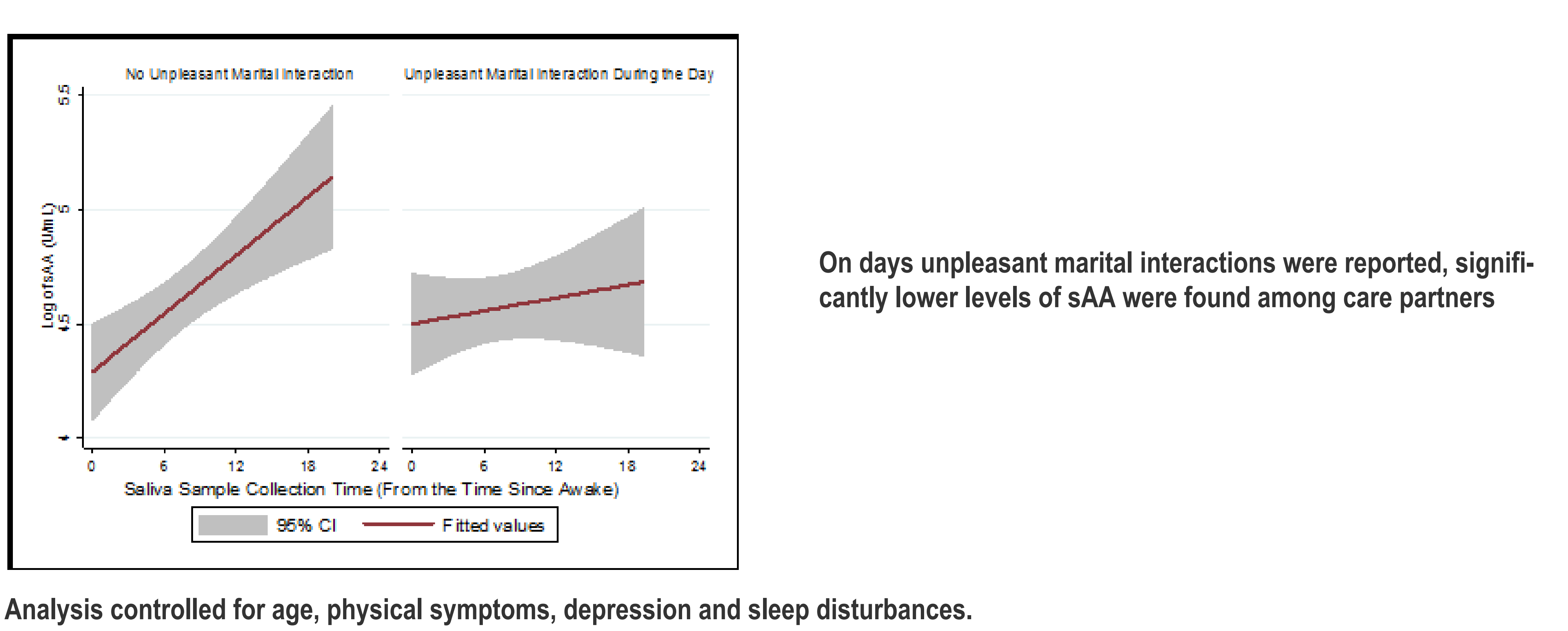

Conclusions

Caring for a spouse even at the early stages of impaired cognitive functioning is associated with

significant psychological distress
Caring exacts a physiologic toll on the care partners' body

(he HPA and

Unclear is the effect of type of stressor (behavioral on cortisol and SAA

Special Notes

See Savla, J., Roberto, K. A, Blieszner, R., Cox, M., Gwazdauskas, F. (in press). Effects of Daily Stressors on the Psychological and Biological Well Being of Spouses of Persons with Mild Cognitive Impairment. Journals of Gerontology: Psychological Sciences.

This work was supported by the Commonwealth of Virginia's ARDRAF Fund No. 08-1 and the

For more information contact Tina Savla (jsavla@vt.edu) 